KRISTINE ALDERSON, MICHAEL ARMSTRONG, SCOTTT BAYUS, DR. RAJNEESH MATHUR, DAVID TRUXTON

\title{
Electronic Medical Records: Effectively Managing Change ${ }^{1}$
}

Adopting technology and innovating in the ED are key elements to reducing the cost in the delivery of healthcare. - Ben Miller

Ben Miller, SumCity Hospital's Emergency Room Medical Director and Founding Partner in ER Docs of Florida (ERDF), slowly gathered his things and left the conference room. The meeting was a long and intense one filled with questions. The healthcare system that contracts Miller's physician group was changing its electronic medical record system (EMR). Unfortunately, the third party EMR company would no longer support the current physician documentation software and a change was inevitable.

As part of the American Recovery and Reinvestment Act (ARRA), all healthcare providers were required to adopt and show meaningful use of an EMR. To avoid a penalty, integration had to occur before January 1, 2014. Many hospitals and older physicians struggled with this. This digital change was new to not only physicians but also business leaders.

Miller reflected on the IT changes that had occurred over the past decade as he sat in traffic on his drive home. In 2010, Miller's site was also picked to be the first Florida site to convert to an EMR within its Healthcare system. Prior, all processes were paper-based. His team embraced the challenge and became the first site in the company's history to achieve the Health Information and Management Systems Society (HIMSS) level 7 accreditation and the second hospital in the state of Florida to do so.

Triumph was achieved by overcoming a multitude of hurdles and by establishing a corporate environment conducive to problem-solving. Some of Miller's physicians were on the verge of quitting during the prior integration, unable to adapt. To prevent physicians from leaving, Miller opted to employ medical scribes for all his physicians to document all interactions with all patients. These scribes allowed his physicians to spend more time at the bedside and less time in front of the computer. This benefit was used by all physicians in the Florida market and came at an annual cost of over 1.5 million dollars. Miller knew this was not a sustainable number. Also, the new software was not designed to be used with medical scribes.

As Miller pulled into his driveway, he thought "How can I switch EMR's, eliminate scribe costs, and keep all my doc's happy?" Would this transition be easier because the providers were already accustomed to an EMR? Would it be more troublesome and time-consuming to make the switch now?

\footnotetext{
${ }^{1}$ Copyright (C) 2019, Kristine Alderson, Michael Armstrong, Scott Bayus, Dr. Rajneesh Mathur, David Truxton. This case was prepared for the purpose of class discussion, and not to illustrate the effective or ineffective handling of an administrative situation. Names and some information have been disguised. This case is published under a Creative Commons BY-NC license. Permission is granted to copy and distribute this case for non-commercial purposes, in both printed and electronic formats.
} 


\section{US Healthcare Industry}

Healthcare is one of the highest growth industries in the entire world. According to the Bureau of Labor Statistics, more than 14.3 million people are employed in the healthcare industry, and it's projected that 3.2 million new healthcare related jobs will be created over the next 8 years ("The Growing Field of Healthcare", n.d.). This industry includes a range of players like hospitals, doctors, nursing homes, pharmacies, diagnostic laboratories, medical device manufacturers, and many other components of the health care system ("2018 US Healthcare Industry Overview and Top Trends", 2018). These types of institutions are considered public, non-profit, and private facilities that serve the community in different ways.

\section{Affordable Healthcare Act}

On February 17, 2009, President Obama signed the American Recovery and Reinvestment Act to help the United States economy during its downturn which started in 2007. There were seven components to this act. One of which expanded Health Care, this being titled the Affordable Care Act (ACA). This created an option to have healthcare coverage at the government level, outside of Medicare which already accounted for a large portion of overall healthcare costs along with state-funded Medicaid. During this time, our government also mandated a transition to move all medical documentation to an electronic medical records (EMR) model. This changed procedures for all medical facilities, causing a shift in how medicine was handled and how technological advances were implemented, which in turn caused more work on the backend to document patient diagnosis. Though there was a change to EMR, the patient understood the technology and it helped build some sort of accuracy (Amadeo, n.d.). The increase of governmental influence on healthcare and the mandatory requirement of EMR's drastically increased the urgency in which this program needed to be implemented. The following paragraphs outline the expansive array of healthcare facilities influenced by this legislation.

\section{Types of Healthcare Providers}

\section{Doctor's Office' and Urgent Care Facilities}

Individuals and families used regular private practice physicians for non-emergency issues. These physicians understood patients' histories, medications, and chronic conditions. There was a co-pay for insurance fees required; however, this was less costly than a hospital visit.

Another method of care was Urgent Care facilities, staffed with nurse practitioners, physicians, and physician assistants. They treated simple conditions such as colds. They also handled physicals for school and some of these facilities had the ability to do x-rays. These facilities took insurance, normally an appointment was not necessary and the cost was less than an ER visit ("Know where to go: How to choose between the doctor's office, urgent care and the ER", n.d.).

\section{Hospitals}

A third example of a primary healthcare facility was a hospital. Hospitals provided emergency services to the patient depending on their needs and covered a range of medical offerings from basic health care necessities or training and research for major medical school centers to services designed by an industryowned network. The mix of services that a hospital offered depended almost entirely upon its basic mission(s) or objective(s). A map of the hospitals who were registered with the American Hospital 
Association in the US and hospital fast facts are supplied as Exhibits 1 and 2, respectively ("Fast Facts for U.S. Hospitals 2018", n.d.).

From a patient perspective, the average individual and family wanted to know how their care was handled, what the cost was, what insurance covered and if they were healthy because of the care received. For the hospital, patient billing depended on the agreement with various partnership groups instead of the actual physicians they were contracted under; therefore, the patient may also have received a surprise bill because the treating physician was not considered 'in-network' under their insurance plan. A patient issue arose when the physician was 'out-of-network' and treated a patient without the patient knowing if that diagnosis was covered under the patients' specific insurance plan. This resulted in a surprise bill ("Unwelcome Billing from Emergency Out-of-Network Physicians", 2017). An integrated system that involved the hospital, physicians, patient records, patients and the Emergency Department had the potential to reduce or eliminate surprise billing.

\section{Emergency Department (ER)}

The modern ER had been designed to enhance every aspect of the patient-centered care experience. The clinical area featured the latest technologies in healthcare to complement their world-class emergency physicians, nurses, and other healthcare providers (Guidera, 2018). The majority of doctors were not employed by a specific hospital. They were contracted with a physician partnership working at the hospital. There were democratic, private, corporate groups and hospital-specific physicians ("Types of Practice Opportunities in Emergency Medicine", n.d.).

Hospital administrators used many recruiting methods to select physicians for the ER. The single most important ingredient for a successful strategy was for the entire administrative team to become involved and to analyze the process from the candidate's perspective. Everyone could play a role, whether it were the front receptionist who greets the candidate by name, the staff on the floors during a tour, or the entire executive team that had helped to identify the need and opportunity. A long-term relationship with a new physician could generate millions for the bottom line and help secure futures (Pile, n.d.).

The facility would also reach out to physician partnerships and staffing companies to help with emergency staffing solutions. There was a shortage of physicians and specialists so hospitals got creative to make sure adequate staff was in place. Technological advances would help these facilities find the physicians and specialists they needed to provide the best care for the client.

\section{Virtual care and healthcare advances}

Virtual care had continued to flourish in the healthcare industry as technology evolved. Communication levels were easier to use and aided the patients' ability to reach a physician, nurse or medical facility quickly. Specialists were easier to find in a quick turnaround period because of the technological advances in place. Critical decisions could be made no matter how far away the patient was. This helped lower costs and efficiencies were put in place to move this health care system to the next level(Horner, n.d.).

Other top healthcare technologies being implemented included data analytics software to help with patient interaction and competitor analysis. Artificial Intelligence (AI) with software (for example, Cerebro) alerted clinicians/nurse staffing of shifts as they became available. Clinicians were paid more than staffing agencies due to lower commission required. Staffing flexibility was another aspect of AI that was a benefit to the industry. Another technology advancement was the utilization of blockchain for 
Healthcare. The end goal was a decentralized record system using blockchain independent of EMR's controlling the data. This required a government mandate or EMRs to open up their data silos to private patient information. Next was the internet of Medical things. A physician could use fit bit knowledge as a form of reporting data ("Top 13 Healthcare Technology Innovations of 2018 - ReferralMD Software", 2018).

\section{Electronic Medical Records}

Medical records served many important purposes. They provided a written history of patient/doctor interactions, tracked treatments, passed information on to other physicians, and supported the decision for additional tests and billing. For many years, patient health records were kept through handwritten notes made by the physician on paper charts. The level of detail in the charts would largely be based on the physician's past experience in determining what should be included.

For the patient, their medical records would be kept with their physician and if needed could be requested and mailed to another physician. This process remained largely unchanged until the 2009 Health Information Technology for Economic and Clinical Health (HITECH) Act passed. The act supplied funds from the federal stimulus package to move towards Electronic Medical Records. At this point, the collection and storage of patient charts were moved to electronic files.

The technology related to meeting the EMR requirements was various. One path towards this involved the physician dictating information in a personal recording device. The physician would verbalize the patient visit and make reference to tests or other material. This recording would then be reviewed and typed by the physician or an assistant, creating an entry on the EMR of the patient. Most of the modern dictation equipment used digital voice recorders and USB microphones, eliminating the need for tapes that would have added long term costs to older dictation equipment. An example of Professional Dictation equipment from Olympus is shown in Exhibit 3. This was viewed as the most time consuming and expensive approach.

Another option involved the use of medical scribes. With this approach, physicians were followed by a medical scribe during their patient visits. The scribe would take notes and complete the EMR in real time using application specific software. This technology allowed the physician to focus on the patient. Many of the scribes used in physicians' offices and hospitals were contracted employees supplied by large medical scribe companies. One of the largest and most used scribe companies was Scribe America (www.scribeamerica.com). For a fee, these contract companies could supply scribes to meet the individual demands of the medical office. Downsides were the extra cost of employing a scribe and an additional person in the exam room.

Then there were TeleScribes, which took the scribe concept one step further. In this case, the physician would wear a small camera, either as a lapel or assistive glasses like the google glass. The physician/patient interaction could be recorded to be typed in the future or it could be live streamed. In either case, there was a medical scribe that translated the experience into an EMR. TeleScribes were often offered through a service similar to contract scribes mentioned above. An example of Tele Scribe workflow can be found in Exhibit 4. This option included the additional cost of the video hardware and the remote scribe but did not add an additional person to the exam room.

An alternate option was for the physician to complete the EMR forms during the patient examination. In this case, the physician would carry a laptop or tablet during the exam and complete the EMR while 
consulting with the patient. There were 2 major ways that the EMR could be completed. The first involved the physician typing notes as he or she conversed with the patient. The other involved the use of voice recognition software embedded into the EMR program which converted the physician voice commands to text. An example screenshot of a physician interface is shown in Exhibit 5. The advantages of this option were decreased labor cost, reduction in the medical staff involved in the patient consultation and reduced review time of the notes after patient visits. The downsides included an increased initial cost due to equipment and an increase in duties for the physician.

\section{Medical Scribe Companies}

\section{How they operate}

Typical with most hospitals and medical offices, scribes were employed to keep accurate EMR's during patient interviews, symptoms diagnosis, and caregiving. Scribes were also employed by the medical group to document and $\log$ billing for physicians. Traditionally scribes were billed at a rate of approximately $\$ 20$ per hour and were contracted through Scribe America by ERDF and assigned one scribe per physician. In a typical ER like SumCity Hospital's there would be at least one scribe on staff during the 24 working hours a day, seven days a week. This costed the hospital, at a minimum, $\$ 6,720$ per week. This ultimately came out of the practice's profit, costing them thousands of dollars each year.

There have been studies looking at the cost-effectiveness of employing medical scribes. A 2013 study compared the hourly cost of scribes to the hourly cost of physicians in the ED (Harris, 2013). The cost of employing scribes was estimated at \$20/hour and ED physicians were \$180/hour. The cost disparity allowed the ED to budget nine (9) scribe hours for every physician hour that was reduced. Scribes were estimated to be roughly 20 percent as productive as a physician. In the end, the study found significant improvements in patient critical areas such as patients per hour, critical care, length of stay, Door-toDoctor time, and down-coded charts.

\section{ER Docs of Florida}

ER Docs of Florida (ERDF) was a medical group owned and led by physicians that leveraged business support services, capital, and a network of physicians, nurse practitioners, and physician assistants. Founded in 2015, ERDF now served nearly 6 million patients annually at over 200 sites in 22 states, offering emergency, hospitalist and observation medicine to hospitals. Across the country, ERDF was continuing to expand, bringing more physician groups on board and driving operational improvement and implementing clinical care across the country.

\section{Scribe America}

Scribe America was a private company and business partner to ERDF. Established in 2003, Scribe America was the largest and most frequently used medical scribe company with more than 15,000 employees in 50 states providing professional services for over 2,600 clients (TeleScribes, n.d.)

\section{SumCity Hospital}

Although SumCity Hospital was the first hospital in the healthcare system to successfully transition to and implement an EMR system, there were underlying attributes of the facility, e.g. the demographics of the patient population and lingering legal and insurance issues, that continued to plague progress towards 
a more streamlined and economically friendly system of EMR. The main component to developing a successful hospital-wide change of any type, let alone advancements in technology, was a willingness amongst the employees to do so. The demographics of the physicians employed at SumCity Hospital varied greatly, which didn't necessarily preclude a successful introduction of new or different technologies. But with physician ages ranging from 29 to 62 years of age, Miller was not surprised that previous technological implementations were met with varying degrees of understanding as well as an initial hesitance and unwillingness to conform to new ideas.

As previously mentioned, the current EMR system that was in place costed over 1.5 million dollars a year. The cost of scribes to the provider group annually in conjunction with increased overhead (malpractice, benefits, salary, etc.) costs were putting more pressure on Dr. Miller and his management team to find a way to decrease the costs associated with EMR.

For Dr. Miller, maintaining profitability while continuing EMR compliance had also turned many of his staffed physicians against him. Veteran physicians presented poor attitudes, an unwillingness to comply and others sought out other employment options. Apparently, the belief came from a thought process that assumed scribes were to be provided by the practice and the change to electronic medical records was implemented by members of the local in-house management team. Contrary to popular belief, their thought process was flawed as all hospitals were mandated to make the change to EMR at a national level over a given time period.

A reoccurring issue with the hired scribes was their inability to legitimately comprehend the physician's conversation and accurately scribe the conversations. This led to larger problems when attempting to bill for procedures and receive payments from insurance companies. If a scribe failed to accurately document information provided by the physician, those deficiencies could have long term ramifications down the road. Humana \& Aetna have withheld payments in excess of 2 million dollars from the practice. The trickledown effect of inaccurate information being documented had drastic affects on the practice's reimbursement system and overall profitability.

\section{The Decision}

After much mental deliberation, Miller knew that ERDF had one opportunity to engage his physicians. This decision would not only affect the pilot site but would set the stage for each additional site. Likewise, he realized that he had just a single chance to set the stage for his physicians. Regardless, the new documentation software had to be implemented. The following solutions were considered:

1. Continue to Use Scribes with the New Software - One option for ERDF was to continue to use medical scribes for all of their physicians. This decision would not disrupt employee morale, would ensure $100 \%$ physician retention, and would not require additional physician training. The medical scribes could be repurposed and given additional roles/duties at work. The medical scribes could also ensure that all the charts were completed and that all the appropriate charting components were completed to ensure maximal reimbursement. This option would not add any costs, however, there would be no direct savings.

2. Remove Scribes with the Implementation of the New Documentation Software - With the implementation of the new documentation software, all of the providers would have to undergo training. Along with the software training, workflow without a scribe would be integrated into their training. Some of the money saved could be utilized for bonuses or raises for the providers. 
3. Remove Scribes before the Implementation of the New Documentation Software - Prior to the new software implementation, providers could be monetarily incentivized to work without a medical scribe. This strategy would allow providers to adjust and fine-tune their workflow without a scribe. When the new software is implemented, providers would only have to adjust to the new software and not a new workflow.

4. Allow Physicians to Independently Pay for Their Own Scribes - ERDF could stop paying for medical scribes and allow physicians to independently pay for their own medical scribes. This could be done as a payroll deduction and shift more of the ownership responsibility onto the providers. Physicians would have the flexibility of scheduling scribes for all of or part of their entire clinical shift. ERDF would save money related to the direct costs related to scribes, however, there could be additional costs associated with ensuring each provider had their preferences matched. Systems would have to be developed to ensure that medical scribe schedules were adjusted if there were physician call offs or changes in schedules. 


\section{References}

2018 US Healthcare Industry Overview and Top Trends | Quantzig. (2018, August 27). Retrieved from https:/www.businesswire.com/news/home/20180827005337/en/2018-Healthcare-Industry-OverviewTop-Trends-Quantzig

About USACS | Hospital Careers and Management. (n.d.). Retrieved August 31, 2018, from https://www.usacs.com/about-us

Amadeo, K. (n.d.). What Did ARRA Really Do? Retrieved August 31, 2018, from https://www.thebalance.com/arra-details-3306299

Digital Dictation Equipment. (n.d.). Retrieved August 30, 2018, from http://medical.olympusamerica.com/technology/digital-dictation-equipment

Electronic Medical Record (EMR) Software. (n.d.). Retrieved August 30, 2018, from http://www.chartlogic.com/emr/

Fast Facts for U.S. Hospitals 2018 | AHA. (n.d.). Retrieved August 30, 2018, from https://www.aha.org/statistics/2018-01-09-fast-facts-us-hospitals-2018

Florida Hospital North Pinellas. (n.d.). Retrieved August 31, 2018, from https://www.floridahospital.com/north-pinellas

Guidera, M. (2018, June 11). The Emergency Department (ER). Retrieved August 31, 2018, from https://www.hopkinsmedicine.org/emergencymedicine/patient_information/index.html

Harris, R., Switaj, M., EmCare North Division, \& EmCare. (2013, July 13). Are Medical Scribes Worth the Investment? Retrieved March 20, 2019, from https://www.beckershospitalreview.com/patientflow/are-medical-scribes-worth-the-investment.html

Horner, L. (n.d.). How healthcare technology will change in 2018. Retrieved August 31, 2018, from https://www.beckershospitalreview.com/healthcare-information-technology/how-healthcaretechnology-will-change-in-2018.html

Know where to go: How to choose between the doctor's office, urgent care, and the ER. (n.d.). Retrieved August 31, 2018, from https://www.bcbs.com/articles/know-where-go-how-choose-between-doctorsoffice-urgent-care-and-er

Losing the Art of Medicine | Healthcare. (2017, September 16). Retrieved August 31, 2018, from https://theshift.usacs.com/science-vs-art-in-medicine-and-the-use-of-medical-scribes/

Pile, D. (n.d.). 10 Steps for Hospitals to Follow to Recruit New Physicians. Retrieved August 31, 2018, from https://www.beckershospitalreview.com/hospital-physician-relationships/10-steps-for-hospitalsto-follow-to-recruit-new-physicians.html

TeleScribes. (n.d.). Retrieved August 30, 2018, from

https://www.scribeamerica.com/telescribes_how_it_works.html 
The Growing Field of Healthcare. (n.d.). Retrieved August 31, 2018, from http://www.careerprofiles.info/growing-healthcare-industry.html

Top 13 Healthcare Technology Innovations of 2018 - ReferralMD Software. (2018, July 24). Retrieved August 31, 2018, from https://getreferralmd.com/2018/01/future-healthcare-technologyadvancements-2018/

Types of Practice Opportunities in Emergency Medicine. (n.d.). Retrieved August 29, 2018, from http://www.aaemrsa.org/get-involved/residents/types-of-practice

Unwelcome Billing from Emergency Out-of-Network Physicians. (2017, February 03). Retrieved August 31, 2018, from https://catalyst.nejm.org/out-of-network-physicians-emergency-billing/

Who We Are. (n.d.). Retrieved August 31, 2018, from https://www.scribeamerica.com/who_we_are.html 


\section{Biography}

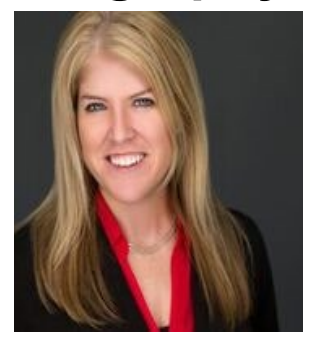

Kristine Alderson has been working with Wells Fargo since 1998. She is an experienced Relationship Manager with a demonstrated history of working in the financial services industry. She is skilled in Proposal Generation, Risk Management, Banking, Business Development, and Strategic Planning. She manages clients within the Government Banking industry nationally. She is a strong sales professional who is currently, a Graduate Student at USF. She received her Competent Communicator certification with Toastmasters International, Inc. She is a member of the West Florida Women's Team Member Network. She is a mom of two teenagers. She loves to be involved in her kids' activities which includes volleyball, band, and baseball. She also enjoys playing both the guitar and the piano.

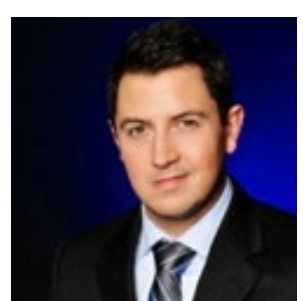

and golfing.
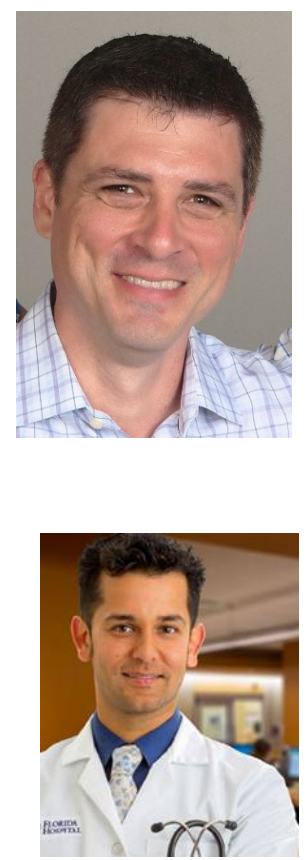

Michael Armstrong is in his 5th year as a District Manager with Cook Medical's Vascular Division, a global supplier of medical devices and the largest privatelyowned medical device company in the world. The former US Navy Petty Officer is responsible for a territory that includes more than 240 hospitals in South Florida and pulls in over three million in revenue a year. He not only manages the clinical aspects of these accounts but also all business activities including contract compliance and purchasing programs. He enjoys playing hockey, fishing, hunting

Scott Bayus has been working at Universal Orlando Resort since 2015. He studied Mechanical Engineering at the University of South Florida. While employed at the Bureau of Reclamation, Scott was given oversight of the Capital Investment Board and Safety Committee. He then moved on from overhauling 800MW hydroelectric turbines (enough to power over 600,000 houses) at The Grand Coulee Dam in Washington State. Most recently, Scott moved back to Florida to work at Universal Orlando (where he was part of the team that recently opened "Volcano Bay"). Scott, verified Parrotthead, enjoys spending time with three children and visiting some of the roadside oddities found in Florida. He also enjoys restoring antique cars and owns a 1931 Ford Model A.

Dr. Rajneesh Mathur has served as an Emergency Department Medical Director in the Florida Hospital System since 2014. He was elected as 2013 Florida Hospital Physician of the Year by the nursing staff. He is currently serving as Chief of Staff at Florida Hospital North Pinellas. Prior to becoming a Founding Partner with USAcute Care Solutions, Dr. Mathur was a physician partner with Tampa Bay Emergency Physicians. Dr. Mathur graduated from a seven-year medical program through the New York College of Osteopathic Medicine and The New York Institute of Technology. He completed his residency in Emergency Medicine at Henry Ford Macomb. During his residency, Dr. Mathur completed a Fellowship in Policy Studies. He has been AOBEM board certified since 2010. Outside of the ED, Dr. Mathur enjoys biking, spending time with his two children, and entrepreneurship. 


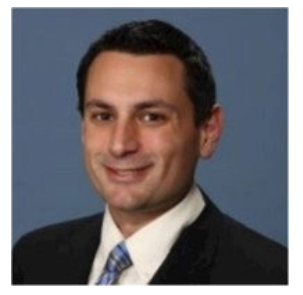

David Truxton is a Vice President with the Kolter Group a real estate development company that specializes in the acquisition, development, and disposition of land for high-rise condominiums, hotel construction, and development of master-planned communities. Formally David has worked for some of the nation's top homebuilders and has developed over fifty master planned communities and thousands of lots for homes across Florida over the last 15 years. David has a degree in Real Estate Finance from Missouri State University and is an active member of the Affiliated Council of Florida Developers (ACFD) and the Urban Land Institute (ULI). Outside of work David enjoys spending time with his wife and three children frequently visiting theme parks and traveling. 


\section{Exhibit 1: Hospitals registered with the American Hospital Association in the US}

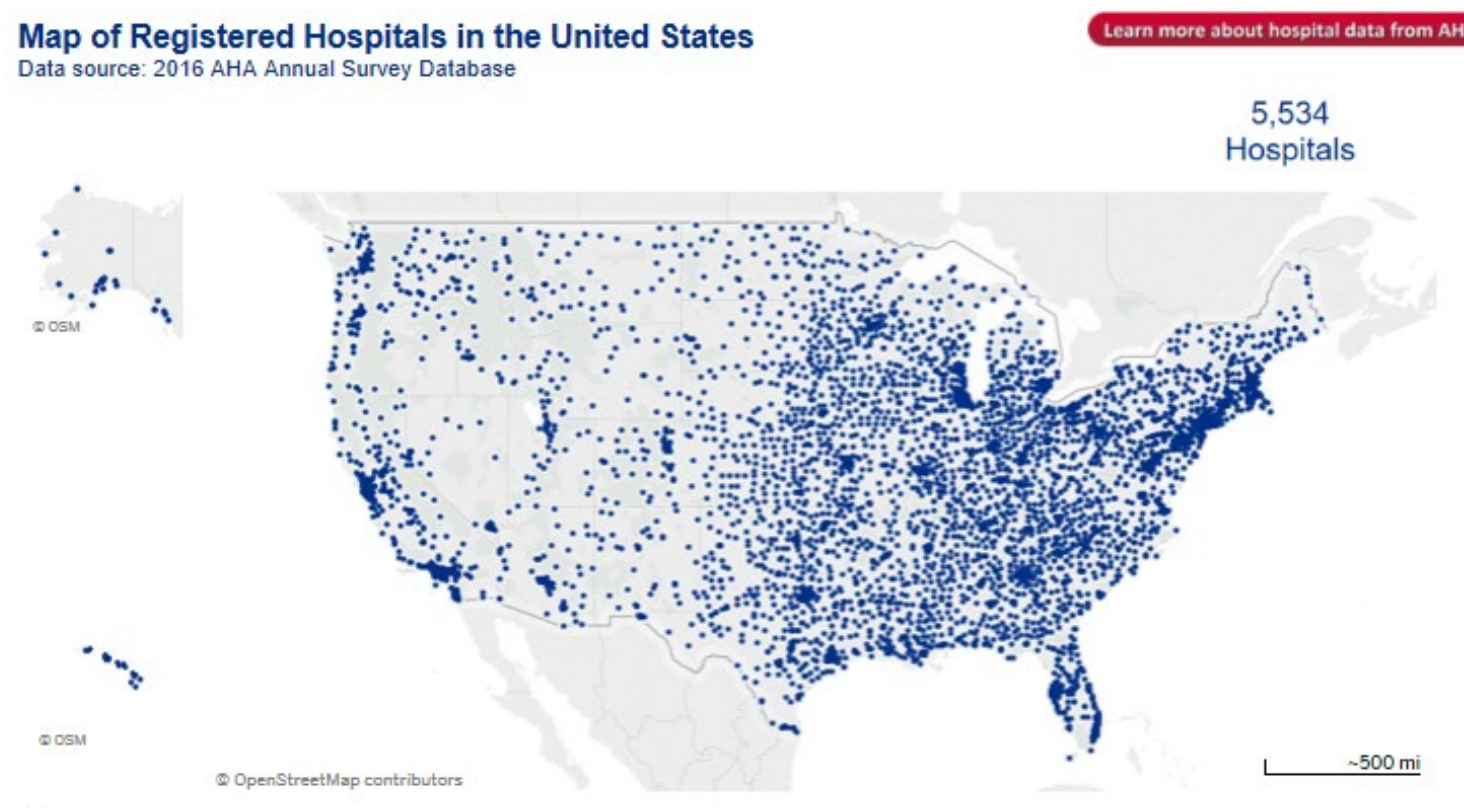

Source: Fast Facts for U.S. Hospitals 2018 | AHA. (n.d.). Retrieved August 30, 2018, from https://www.aha.org/statistics/2018-01-09-fast-facts-us-hospitals-2018 


\section{Exhibit 2: Fast Facts}

\begin{tabular}{|c|r|}
\hline Total Number of All U.S. Registered ${ }^{1}$ Hospitals & 5,534 \\
\hline Number of U.S. Community ${ }^{2}$ Hospitals & 4,840 \\
\hline Number of Nongovernment Not-for-Profit Community Hospitals & 2,849 \\
\hline Number of Investor-Owned (For-Profit) Community Hospitals & 1,035 \\
\hline Number of State and Local Government Community Hospitals & 956 \\
\hline Number of Federal Government Hospitals & 209 \\
\hline Number of Nonfederal Psychiatric Hospitals & 397 \\
\hline Other $^{3}$ Hospitals & 88 \\
\hline & \\
\hline & \\
\hline Total Staffed Beds in All U.S. Registered ${ }^{1}$ Hospitals & 894,574 \\
\hline Staffed Beds in Community ${ }^{2}$ Hospitals $^{1}$ Hospitals & 780,272 \\
\hline Total Admissions in All U.S. Registered ${ }^{1}$ Her & $35,158,934$ \\
\hline
\end{tabular}

\begin{tabular}{|l|r|}
\hline \multicolumn{1}{|c|}{ Admissions in Community ${ }^{2}$ Hospitals } & $33,424,253$ \\
\hline Total Expenses for All U.S. Registered ${ }^{1}$ Hospitals & $\$ 991,531,841,000$ \\
\hline \multicolumn{1}{|c|}{ Expenses for Community ${ }^{2}$ Hospitals } & $\$ 902,891,035,000$ \\
\hline & \\
\hline Number of Rural Community ${ }^{2}$ Hospitals & 1,825 \\
\hline Number of Urban Community ${ }^{2}$ Hospitals & 3,015 \\
\hline & \\
\hline Number of Community Hospitals in a System ${ }^{4}$ & 3,231 \\
\hline Number of Community Hospitals in a Network & \\
\hline
\end{tabular}

Source: Fast Facts for U.S. Hospitals 2018 | AHA. (n.d.). Retrieved August 30, 2018, from https://www.aha.org/statistics/2018-01-09-fast-facts-us-hospitals-2018 


\section{Olympus Portfolio}

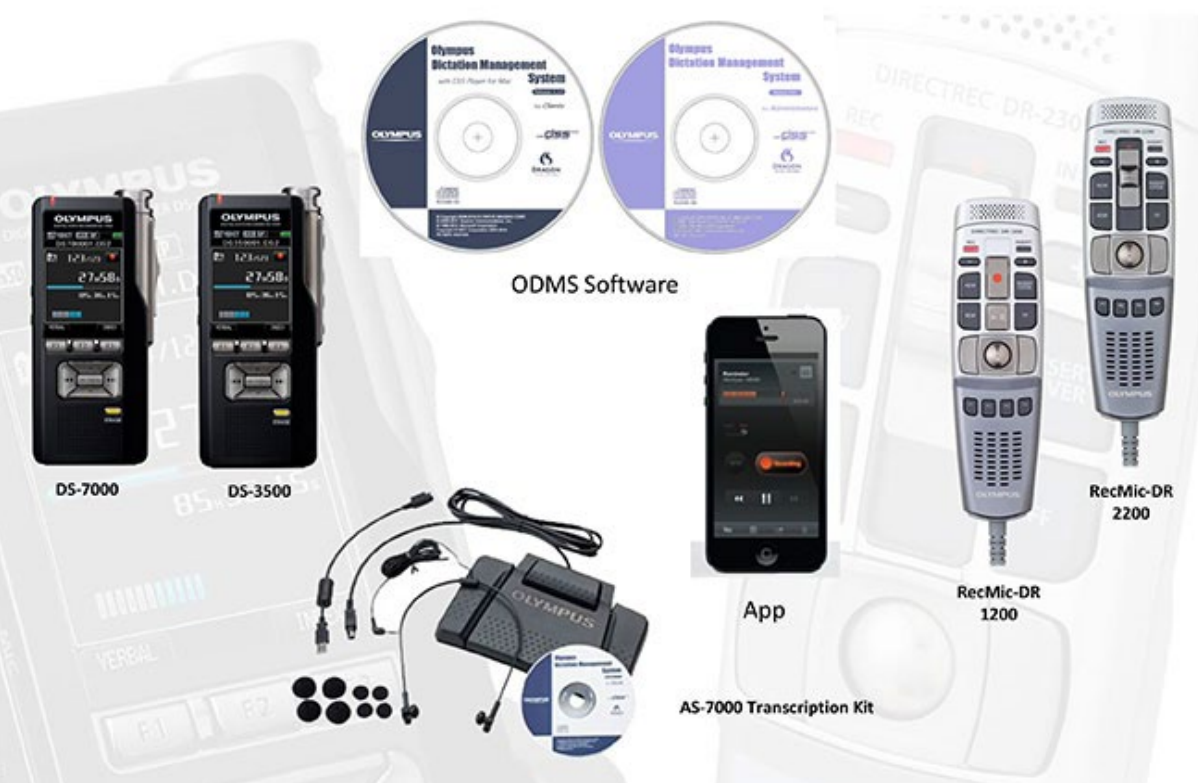

Source: Digital Dictation Equipment. (n.d.). Retrieved August 30, 2018, from http://medical.olympusamerica.com/technology/digital-dictation-equipment 


\section{Exhibit 4: TeleScribe Workflow}

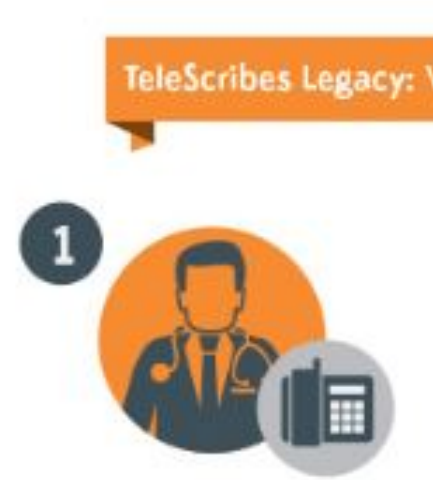

All the provider needs is a working land line phone.

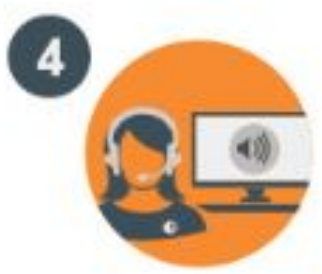

The scribe recelves a Wav or volce recording.

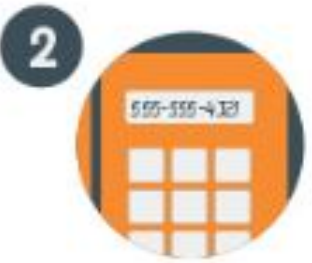

Provider calls into a HIPAA compllant server provided by scribeAmerica using a speclal pin.

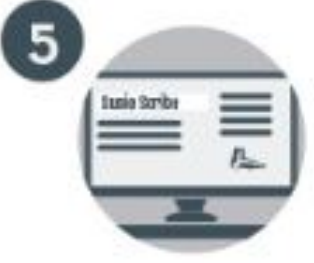

Scribe documents directly Into the EMR using their own username and password.

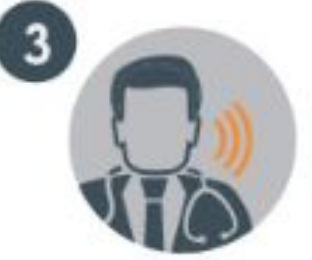

Provider dictates thelr records.

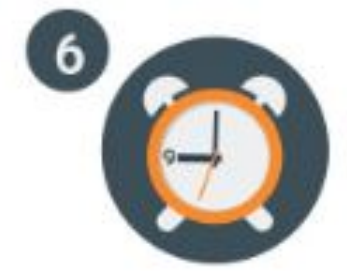

If provider submits calls throughout the day, documentation can be completed by $9 \mathrm{p} . \mathrm{m}$. each night.

Source: TeleScribes. (n.d.). Retrieved August 30, 2018, from

https://www.scribeamerica.com/telescribes_how_it_works.html 


\section{Exhibit 5: Sample screenshot of Physician interface}

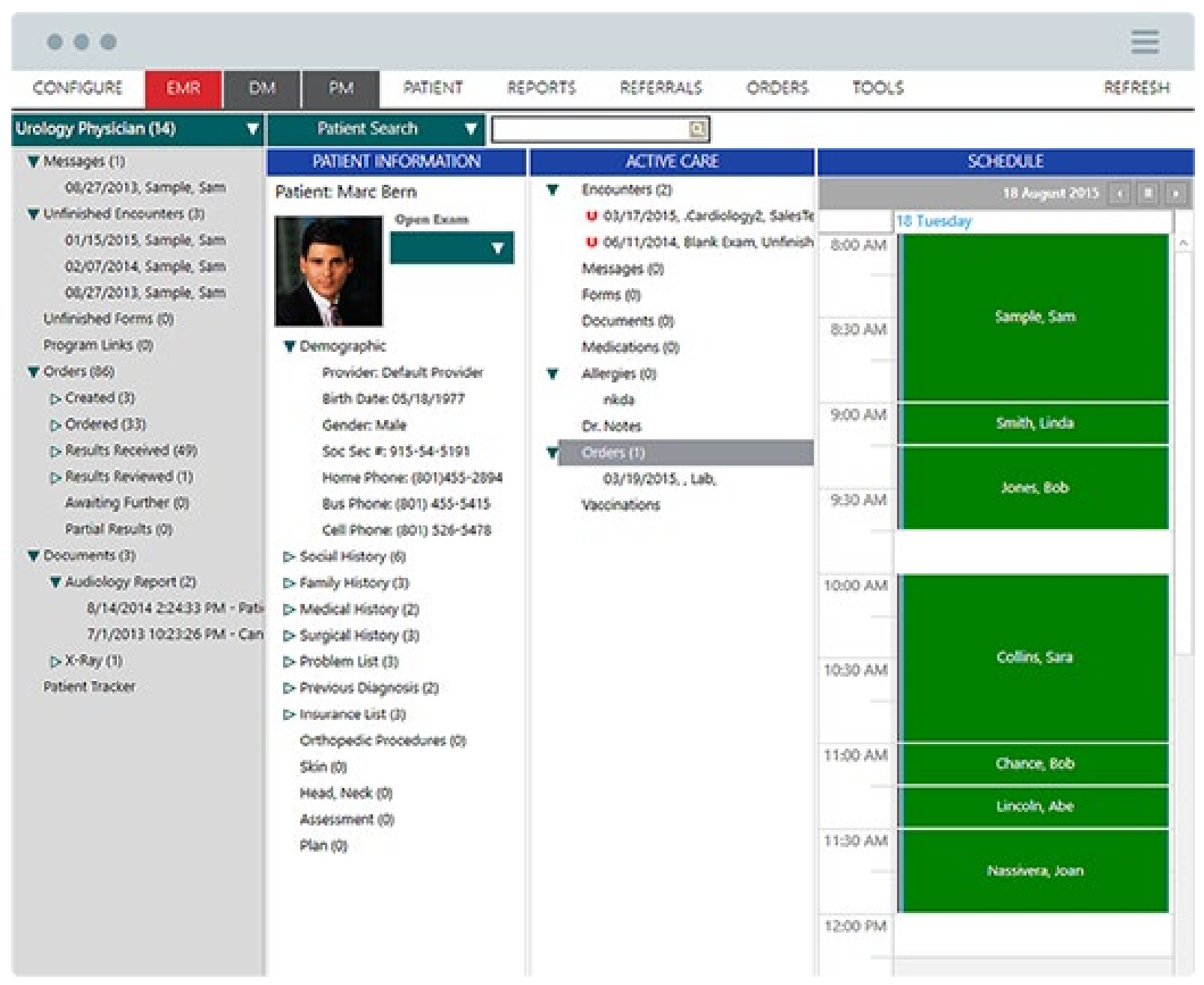

Source: Electronic Medical Record (EMR) Software. (n.d.). Retrieved August 30, 2018, from http://www.chartlogic.com/emr/ 